\title{
PONTOS DE INFLEXÃO NA IDEIA DE GESTÃO EDUCACIONAL DE HELOÍSA LÜCK
}

Zionel Santana ${ }^{1}$

\begin{abstract}
RESUMO: O objetivo deste artigo é aproximar a delimitação conceitual em Heloíse Lück (2006) de gestão paradigmática a ideia de paradigma de Thomas Kuhn (2007). A delimitação conceitual de gestão paradigmática está presente na coleção de cadernos de Heloísa Lück (2006) em suas variações. Em Kuhn (2007), a ideia de paradigma foi desenvolvida em sua obra "A Estrutura das Revoluções Científicas". Em um segundo momento aproximamos a delimitação conceitual de Lück (2006) sobre gestão da ideia de Follett (1997). O tipo de pesquisa utilizado na produção deste texto foi a bibliográfica de acordo com Köche (2015) que parte da apropriação de conceitos e concepções presentes na literatura. Desta forma adotou-se o método hipotético-dedutivo (MARCONI; LAKATOS 2009) a partir do problema levantado sobre aproximação da ideia de gestão e da ideia de paradigma. O resultado da pesquisa aponta para o estranhamento entre a delimitação conceitual de gestão paradigmática em Kuhn (2007) e Follett (1997). A hipótese de trabalho nesta pesquisa parte da suposição que a delimitação da ideia de gestão de Lück (2006) traria possíveis interpretações diferentes sobre a gestão do ensino na educação brasileira.
\end{abstract}

Palavras-chave: Gestão. Escola. Descentralização. Educacional.

\section{INFLECTION POINTS ON IDEA OF EDUCATIONAL MANAGEMENT OF HELOÍSA LÜCK}

\begin{abstract}
The purpose of this article is to present the conceptual delimitation in Heloíse Lück (2006) paradigmatic management the idea of Thomas Kuhn's paradigm (2007). The conceptual delimitation of paradigmatic management is present in the collection of notebooks of Heloísa Lück (2006) in its variations. In Kuhn's (2007) idea of paradigm was developed in your work the structure of scientific revolution (1970). The result of the research points to the estrangement between the conceptual delimitation of paradigm management in Kuhn (2007) and Follett (1997). The type of research used in the production of this text was bibliographic according to Köche (2015), which starts from the appropriation of concepts and concepts present in the literature. In this way, the hypothetical-
\end{abstract}

\footnotetext{
${ }^{1}$ Doutor em Filosofia pela Universidade Gama Filho/RJ (2011). Atualmente é professor de Sociologia, Ciência Política da Faculdade Cnecista de Varginha. Professor na UNINCOR/Três Corações no Programa do Curso de Mestrado em Gestão e Planejamento do Ensino.
} 
deductive method was adopted (MARCONI; LAKATOS 2009) based on the problem raised about the approximation of the management idea and the paradigm idea. The working hypothesis in this survey part of the assumption that the delimitation the idea of management of possible different interpretations about Lück (2006) would bring the management of teaching in brazilian education.

Keywords: Management. School. Decentralization. Educational.

\section{PUNTOS DE INFLECCION EN LA IDEA DE LA GESTION EDUCATIVA DE HELOÍSA LÜCK}

RESUMEN: El objetivo de este artículo es aproximar la delimitación conceptual en Heloíse Lück (2006) de gestión paradigmática la idea de paradigma de Thomas Kuhn (2007). La delimitación conceptual de la gestión paradigmática está presente en la colección de cuadernos Heloísa Lück en sus variaciones. En Kuhn (2007), la idea del paradigma se desarrolló en su trabajo de la Estructura de la Revolución Cientifica (1970). En un segundo momento nos acercamos a la delimitación conceptual de la gestión de ideas de Follett (1997). El tipo de investigación utilizada en la producción de este texto fue la bibliográfica según Köche (2015) que parte de la apropiación de conceptos y conceptos presentes en la literatura. De esta forma, se adoptó el método hipotético-deductivo (MARCONI; LAKATOS 2009) del problema planteado sobre la aproximación de la idea de gestión y la idea de paradigma. El resultado de la investigación apunta a la extrañeza entre la delimitación conceptual de la gestión paradigmatica en Kuhn (2007) y Follett (1997). La hipótesis de trabajar en esta investigación parte de la suposición de que la delimitación de la idea de Lück (2006) traería posibles interpretaciones diferentes sobre la gestión de la enseñanza en la educación brasileña.

Palabras Clave: Gestión. Escuela. Descentralización. Educativo.

\section{Introdução}

A ideia desenvolvida por Thomas Kuhn (2007) nos leva a uma reflexão sobre a afirmação de Heloísa Lück (2006) em sua coleção de cadernos sobre Gestão Educacional: uma questão paradigmática. Lück (2006) faz uma aproximação da ideia de paradigma, a qual não se refere a sua matriz conceitual. Desta forma, levantamos a questão de qual matriz conceitual ela estaria falando. Assim, aproximamos a ideia de paradigma de Lück (2006) da ideia de paradigma em Kuhn (2007) na sua obra "A 
Estrutura das Revoluções Científicas". Lück (2006) faz uma associação direta do conceito de paradigma para a ideia de gestão educacional.

O texto aqui, à princípio empreende na aclaração das limitações a esse respeito. Pois coloca sob suspeita que a gestão talvez, não seja, um paradigma entre as Ciências Sociais e nem as Ciências aplicadas. Pois, desta forma Lück (2006) não poderia de forma solipsista entrelaçar a ideia de paradigma com a ideia de educação.

[...] que o conceito de gestão tendo em vista seu caráter paradigmático não se refere a este ou aquele segmento, mas ao sistema de ensino como um todo, tanto horizontal e quanto verticalmente, e, portanto, não se constitui em uma função circunscrita a quem detém o cargo/função maior de uma unidade de trabalho (LÜCK, 2006, p. 37).

$\mathrm{Na}$ concepção de Kuhn (2007) o paradigma é compartilhado com uma comunidade de pesquisadores, ou um grupo de cientistas que o adotam como possíveis respostas aos problemas enfrentados no cotidiano de seus trabalhos. $\mathrm{Na}$ afirmação de Lück (2006) transparece-nos o uso da ideia de gestão como um paradigma dissociado de um grupo de pesquisa e colegas cientistas que deveriam compartilhar da mesma ideia, mesmo que divergente em alguns aspectos.

Primeiramente, a gestão e o paradigma são concepções diferentes. A gestão é resultado das reflexões da Ciência da Administração, aceito na comunidade de cientistas. O Paradigma, pode ser ou não produzido por um cientista ou uma comunidade de pesquisadores que serve para resolver o "quebra-cabeça", que aos poucos vai sendo compartilhado e aceito por cientistas e comunidade de pesquisadores (KUHN, 2007). Não há uma relação direta entre a gestão e o paradigma. Desta forma, temos o desafio de compreender à ideia de Kuhn (2007) sobre paradigma para aproximar da ideia paradigmática de gestão de Lück (2006).

Na segunda parte do texto temos a compreensão de gestão a partir de Follett (1997), e de posse desses conceitos, aproximaremos da concepção de Lück (2006) sobre Gestão. Espera-se aclarar os resultados objetivos sobre a possível associação ou não da ideia luckiana de Gestão paradigmática aplicada ao Sistema de Ensino no Brasil.

\section{Constituição da pesquisa e do método}

A pesquisa utilizada na produção deste texto foi a bibliográfica. De acordo com Köche $(2015$, p, 122) "na pesquisa bibliográfica o investigador irá levantar o 
conhecimento disponível na área, identificando as teorias produzidas analisando-as e avaliando sua contribuição para auxiliar a compreender ou explicar o problema objeto da investigação". Portanto, parte da apropriação de conceitos e concepções na literatura. Aqui em específico, Lück (2006) e Kuhn (2007). Desta forma adotou-se o método hipotético-dedutivo (MARCONI; LAKATOS 2009) a partir do problema levantado sobre aproximação da ideia de gestão e da ideia de paradigma. Na concepção de Marconi e Lakatos (2009) o método hipotético-dedutivo parte de uma questão que suscita dúvidas-, ao qual pressupõe propostas provisórias a partir de teorias e hipóteses de trabalho. Assim, pretende apontar possíveis caminhos diferentes dos já apresentado nas teorias estudadas.

\section{Constituição da ideia de paradigma}

"Um paradigma é aquilo que os membros de uma comunidade compartilham e, inversamente, uma comunidade científica consiste em homens que partilham um paradigma" (KUHN, 2007, p. 221). O paradigma pode surgir inicialmente de um pesquisador que a partir de uma nova perspectiva consegue respostas aos velhos problemas. A descoberta desse novo paradigma pode ser compartilhada com mais pesquisadores, ou a comunidade de pesquisadores.

Para Kuhn (2007) com o surgimento de um novo paradigma não significa o abandono do objeto de observação ou do fenômeno. Mas, sim um olhar em uma outra perspectiva sobre o mesmo fenômeno/objeto que origina novos questionamentos. Assim, Kuhn (2007) demonstra que um paradigma acaba direcionando o olhar dos cientistas para os velhos problemas e as anomalias, para que os mesmos encontrem possíveis respostas ainda não pensadas.

Normalmente, somos condicionados pelo paradigma a enxergar aquilo que é possível ver dentro da moldura do próprio paradigma. O que de certa forma, limita o pesquisador e a sua comunidade em observar o fenômeno, e a ele apresentar possíveis respostas que permanecem limitadas ao campo de visão.

As revoluções Cientificas de certa forma, são resultados do surgimento de novos paradigmas que provocam novas perspectivas sobre os fenômenos, contribuindo para as mudanças, assim Kuhn entende que a Revolução é "[...] a formulação de 'quebracabeça' e de soluções quando possível devem ser simples, dotados de coerência 
interna e plausíveis, vale dizer, compatível com outras teorias disseminadas no momento" (KUHN, 2007, p. 232).

Mas isso, não garante que o novo paradigma passe a preparar um pesquisador para as novas pesquisas, mas garante lhe novas condições em perceber novas possibilidades (KUHN, 2007, p. 97). Isso possibilita ao cientista testar outros modelos para encontrar novos caminhos para a pesquisa. Esses novos modelos são compartilhados entre os pesquisadores e outras comunidades, - não há nenhuma regra em que os paradigmas fiquem restritos somente aos pesquisadores e a sua comunidade. Podemos observar na história das Ciências a demonstração que o paradigma tende a ser adotado por diferentes pesquisadores e comunidades, quando esse modelo responde melhor os problemas enfrentados do que a moldura do antigo paradigma.

O paradigma da educação no qual Lück (2006) se refere em gestão educacional na sua série de cadernos, não tem a sua origem na educação. A gestão "[...] se assenta sobre bons procedimentos de administração bem resolvidos e os supera mediante ações de sentido mais amplo, maior compromisso de pessoas com processos sociais" (LÜCK, 2006, p. 111). E também:

[...] a gestão educacional, realizada em carácter amplo e abrangente, do sistema de ensino, [...]. Isso porque é pela gestão que estabeleceu unidade, direcionamento, ímpeto, consistente e coerência à ação educacional, a partir de paradigma, ideário e estratégias adotadas para tanto. Porém, é importante ter em mente que gestão é uma área-meio, e não um fim em si mesma (LÜCK, 2011, p. 18).

O novo paradigma não é um olhar sobre as respostas já dadas, "dos bons procedimentos", "bem resolvidos". Os arranjos fornecidos pelo paradigma anterior foram válidos e permanecem assim, se a perspectiva, ainda fora do velho paradigma (KUHN, 2007).

O surgimento de um novo paradigma nos aponta para aqueles problemas que 0 velho paradigma não tem respostas, e ao mesmo tempo, nos direciona a pensar nas anomalias do fenômeno. Isso é, há uma reformulação do "quebra-cabeça". A percepção de novos problemas só é possível a partir de um novo paradigma que possibilita um novo alcance. Desta forma, a compreensão de Lück (2006, p. 69) sobre a gestão educacional paradigmática se aproxima mais de uma visão reformista da 
educação, pois tenta, mesmo ainda com muito esforço apresentar uma visão que julga se bom na administração escolar com uma nova roupagem, "bons procedimentos da administração bem resolvidos", "ideário", "estratégias", e "uma área-meio".

O risco em introduzir uma ideia reformista no sistema de ensino a partir da interpretação da Lei no 9.394, de 20 de dezembro de 1996, sobre a gestão educacional, podemos cair em uma leitura conservadora, valorativa e não inovadora. A gestão não é um paradigma como afirma Lück (2006), é muito mais um reflexo paradigmático. $E$, não é da sua esfera mudar uma realidade fragmentada para uma unidade. As afirmações lückianas são corretas na medida em que as suas observações, ela constata os efeitos do paradigma mecanicista na administração. Tais influências é que condicionaram a compreensão da realidade dual e fragmentada. Se assim o fosse, a função da administração também seria de unificação da realidade fragmentada há muito tempo. A conclusão possível é que não havia uma consciência sobre a realidade fragmentada que se manifestasse. Ela permaneceu presa a moldura do paradigma mecanicista. A fragmentação da realidade é resultado dos efeitos paradigmáticos. Portanto, o administrador de uma organização só poderia entender o mundo assim, fragmentado. Essa concepção muda à medida que se instala um novo paradigma.

\footnotetext{
Uma forma de conceituar gestão é vê-la como um processo da competência e de energia de pessoas coletivamente organizada para que, por sua participação ativa e competente, promovam a realização, o mais plenamente possível dos objetivos de sua unidade de trabalho, no caso os objetivos educacionais (LÜCK, 2013, p. 21).
}

A tônica recai sobre as pessoas e seus papeis performáticos, reforçado na administração escolar, que tende a se repetir nas pessoas envolvidas no novo processo. Observa-se que a definição de Lück (2006) de gestão sobrecarrega o humano com a mesma carga da administração escolar, apontado como o insucesso do processo administrativo. Este pensamento demonstra uma contradição interna, com o seguimento de um novo paradigma que tem na sua origem na psicologia e a fisiologia segundo Follett (1997).

Para Kuhn (2007) o novo paradigma nos aponta para as anomalias de um fenômeno, e nos orienta para possíveis respostas, ainda não pensadas. A questão é que, quais anomalias Lück (2006) encontrou na Administração Escolar? Na comunidade de pesquisadores, que possíveis respostas ela nos apresenta? São desafios que ainda 
permanecem, não só a Lück (2006), mas a todos os pesquisadores e a comunidade científica que tem o Sistema de Ensino/Educação como um fenômeno da observação.

Normalmente, elementos/respostas do velho paradigma não acompanham o novo paradigma, "[...] quando mudamos os paradigmas, muda com ele o próprio mundo" (KUHN, 2007, p. 147). Um dos elementos comuns ao novo paradigma é a elaboração de instrumentos que sejam capazes de orientar o novo olhar sobre o fenômeno.

Quando Galileu seguiu as intuições de Copérnico e Kepler, percebeu que suas suposições eram anomalias do sistema planetário (KUHN, 2007). Isto é, o paradigma geocêntrico não respondia as suas indagações. Galileu só consegui ver o que eles já anunciavam com a troca de paradigma. O heliocentrismo possibilitou a compreensão das anomalias e montar o "quebra-cabeça".

Essa teoria foi capaz de explicar para a época os problemas formulados por Copérnico e Kepler. O "quebra-cabeça" foi montado em uma outra perspectiva. Esse paradigma serviu a muitos cientistas como uma moldura para pensar os fenômenos de observação de diversas ciências e proporcionou grandes avanços na comunidade cientifica.

A intuição de Copérnico e Kepler não eram respondidas pelo velho paradigma geocêntrico, as anomalias também não eram passíveis de respostas, ao adotarem o modelo da teoria heliocentrismo, o olhar de Galileu mudou sobre o mesmo fenômeno sobre o universo e o movimento dos astros que foram possíveis responder a problemas que não seriam possíveis com o velho paradigma (KUHN, 2007). Portanto, a única coisa presente no novo paradigma do velho paradigma é somente o fenômeno em uma outra perspectiva. Não é possível essa compreensão de Lück (2006) em apresentar respostas do velho paradigma para o novo paradigma. Há em Lück (2006) a tentativa em salvar a administração com a gestão, e manter elementos paradigmáticos da velha administração na gestão. A gestão é reflexo de um novo paradigma que tem suas características próprias, revolucionária e não é salvífica e reformista. Os paradigmas tendem a uma revolução e não a uma reforma (KUHN, 2007).

O paradigma tem a função de orientar os pesquisadores e a comunidade científica para novas descobertas. Não é esta a função da gestão, ser um paradigma e nem salvífica. Parece-nos ser mais modesto o seu papel. Outro aspecto apresentado por Kuhn (2007) na troca de paradigma é o aparecimento da crise. O autor pressupõe 
que a crise é um reflexo em um sistema de saberes acumulados em um determinado período paradigmático, que foi desorganizado a partir do novo paradigma, isto é, o "quebra-cabeça" foi desarrumado e precisa ser realinhado. Talvez, a confusão neste momento, seja pela a crise que se estabeleceu na educação e nos saberes desorganizados. Portanto, há a sedução em tentar alinhar o "quebra-cabeça" dentro de um ideário que não existe mais. A reorganização do "quebra-cabeça" não se dá mais com o velho paradigma. Somos traídos pelo ideário mecanicista que seria possível aproveitar o que ele tem de bom. Acreditamos que seria possível uma dialética paradigmática. Todo novo paradigma é uma negação do velho paradigma e ao mesmo tempo, uma autoafirmação.

Todo paradigma nasce como uma tese. A dialética já aconteceu no processo de seu surgimento. Por isso, um paradigma não é passivo de uma prática dialética. Podemos perceber essa realidade no heliocentrismo. Qual era a dialética deste paradigma? Nenhuma! O heliocentrismo é a negação do geocentrismo e ao mesmo tempo, autoafirmação. A gestão é o reflexo paradigmático, ela surge como negação do conjunto de saberes constituídos da administração e ao mesmo tempo é um conjunto de saberes autoafirmativo. Existe uma reorganização interna do sistema de saberes que possibilitava os contextos de fenômenos em uma maneira mais detalhada, em uma outra perspectiva, na qual não seria possível com o velho paradigma.

Quando o paradigma aparece, nasce um novo processo com possíveis repostas à crise e modelos de uma nova organização do "quebra-cabeça" (KUHN, 2007). É o que justifica o aparecimento do paradigma, sua função também é resolver os problemas e as anomalias. Essa necessidade do paradigma é fruto das inúmeras tentativas frustradas em responder aos problemas e as anomalias. Está implícito nesse processo histórico a ideia de evolução.

\section{O modelo mecanicista presente na administração escolar}

Se olharmos o sistema de ensino perceberemos que ele é um "quebra-cabeça" reorganizado a partir da moldura taylorista, fordista e fayolista que responderam bem até a década de 90 (LOURENÇO FILHO, 2007). O sistema de ensino adotou a administração na escola ancorada no paradigma mecanicista que teve a sua origem na física. A administração escolar não foi um paradigma, e sim, resultado da aceitação 
compartilhada pela comunidade de cientistas da administração do novo paradigma. Como já vimos anteriormente que o paradigma pode ser compartilhado com diversos cientistas e diferentes comunidades de pesquisadores. O mecanicismo não originou na administração, outras comunidades também passaram a adotá-lo como possíveis respostas aos novos problemas e anomalias.

Portanto, essa linha de argumentação nos coloca sobre alguns questionamentos. Se a Administração Escolar não foi um paradigma na sua aplicação no sistema de ensino da década de 30 até a década de 90, quais são os argumentos lückianos para justificar que a gestão seja paradigmática a partir do século XXI? Também colocamos sobe suspeita que a gestão não seja um paradigma, mas reflexos paradigmáticos. Ainda, compreendemos que a comunidade de pesquisadores da administração tenha compartilhado um novo paradigma e que tenha resolvido os problemas e as anomalias da administração. Ainda, podemos continuar nesta linha de argumentação que eles adotaram uma nova moldura e foram capazes de uma nova reformulação do "quebra-cabeça", descobriram respostas que ainda eram imagináveis para os problemas e anomalias na administração da sua época.

Qual é o novo paradigma adotado pela comunidade de pesquisadores da administração que mudou a visão sobre a empresa e o seu processo produtivo? A perseguição desta ideia nos leva a um diálogo com Lück sobre gestão educacional, em que paradigma ela está ancorada? É o mesmo da administração quando nos apresenta a gestão como possível respostas as anomalias do processo produtivo? O que é compreensivo que a educação/sistema de ensino adote também o mesmo paradigma compartilhado pela administração, basta compreender a educação como um sistema e a escola como uma organização. A gestão está entrelaçada ao paradigma, mas não se confundem.

\section{Delimitação da ideia de gestão}

A compreensão de gestão paradigmática é a tônica do pensamento de Lück (2006) "o conceito de gestão se dá lentamente na substituição pelo conceito de administração em oposição entre a fragmentação para a unidade de conjunto e da individualização para coletividade" (LÜCK, 2006, p. 69). 
Essa ideia de gestão como já vimos anteriormente, não poderia ser associada a compreensão de paradigma, também já vimos que gestão é muito mais um reflexo do paradigma adotado. A autora concebe a gestão como substituição a administração, talvez não seja uma substituição, mas uma transição que ainda não finalizou todo o seu processo. Não é um abandono da administração em detrimento da gestão, o que não podemos compreender essa argumentação interna da explanação conceitual. " [...] A possibilidade de se denominar como gestão o conjunto de ideias e práticas puras e simplesmente relacionadas a uma administração modernizada, atualizada em seus aspectos operacionais, mantendo-se a antiga ótica de controle sobre coisas, pessoas e ações [...]" (LÜCK, 2013, p.23).

Esse posicionamento reforça a ideia já apresentada anteriormente que a gestão está mais próxima de uma reforma do que uma revolução. A revolução é mais apropriada ao paradigma, do que a individualização. A ideia de individualização e fragmentação da realidade é outro indício das contradições internas conceituais de gestão apresentada por Lück (2006). Desta forma, a autora ainda trabalha com o conceito de dualismo presente do velho paradigma.

Antes de entramos na discussão sobre o conceito de gestão em Follett (1997) podemos ainda, perceber a compreensão de gestão de Lück (2006) nos desdobramentos argumentativos.

“A gestão, portanto, é que permite superar a limitação da fragmentação e da descontextualização e constitui, pela ótica abrangente e interativa, a visão e orientação de conjunto, a partir da qual se desenvolver ações articuladas e mais consistentes" (LÜCK, 2006, p. 43). Talvez, atribuir a ideia de gestão tanta responsabilidade genérica faz com que esse conceito não produza os efeitos práticos que se espera. Isso é compreensivo na medida em que a autora associa gestão ao paradigma.

Em Kuhn (2007) o paradigma tem por um dos propósitos guiar os cientistas a partir de novos instrumentos na observação do fenômeno em outra perspectiva, não nos parece ser esta a função da gestão, ela não tem esse alcance. Ela está mais restrita a uma organização independente de seu tamanho e natureza.

Podemos assim entender que superar uma concepção fragmentada e descontextualizada, só será possível como o abandono do velho paradigma para o novo paradigma, a mudança é uma característica transgressora do paradigma. É o que se espera na gestão. $\mathrm{O}$ abandono do velho paradigma conduz os cientistas a verem os 
fenômenos em um ponto de vista bem diferente do qual as pesquisas não revelam. A percepção sobe a empresa não é mais a mesma, pois o paradigma mudou. A questão que nos resta a saber, é o que mudou?

Em um processo produtivo empresarial, com o paradigma mecanicista a relação entre os sujeitos e os objetos era concebido hierarquicamente, pontuando na égide da subordinação. Compreensivo no modelo mecânico que tudo é constituído por engrenagem, onde as peças de menor valor são substituídas constantemente no processo do movimento produtivo da força. O paradigma mecanicista com suas características da Administração Científica estruturou-se em um arranjo rígido de engrenagens de peças mecânicas. (LOURENÇO FILHO, 2007). Ressaltava a eficiência através de avaliações sistemáticas, acreditando assim no progresso da organização. Esse paradigma é possível de se encontrar nas teorias da administração de Taylor, Ford e Fayol, que derem ênfase nas tarefas, nas estruturas e no controle.

A psicologia e a fisiologia na concepção de Follett (1997) foram responsáveis para a mudança de paradigma, que teve reflexos de como compreender uma organização. A compreensão que a realidade era dual constituída por um sujeito e o objeto da herança cartesiana paradigmática. Estabeleceu-se a visão dos fenômenos entre os idealistas que coloram no sujeito toda a ênfase, que a verdade era a única existência possível na primazia do sujeito sobre o objeto. Por outro lado, os defensores que a única verdade era a experiência objetal. Daí, nasceu à moldura de interpretar os fenômenos entre a subjetividade e objetividade, do racionalismo ao idealismo e a fragmentação.

Follett (1997) entendeu que essa moldura dual mecanicista orientou os cientistas e as comunidades dos pesquisadores a interpretarem os fenômenos. $\mathrm{O}$ que de certa forma, condicionaram os resultados das pesquisas e saberes. Isso é possível ser compreendido nas teorias que vigoravam até o século $X I X$ e $X X$, em que se posicionam tudo em oposição, entre sujeitos e objetos, presentes nas teorias políticas, econômicas, sociais e organizacionais. Um dos fundamentos da teoria econômica liberal denunciado no pensamento de Marx, aquela visão dual do capitalismo em que proletariados, capitalistas, pobres e ricos configuravam uma forte oposição o tempo todo, entre os oprimidos e os opressores, o povo e o governo, os negros e os brancos, os homens e as mulheres. 
Esse exemplar, tenta moldar à realidade, como já percebemos, isso foi compartilhado com diversas comunidades científicas e grupo de pesquisadores. Quando nos referimos à comunidade de pesquisadores da administração, é natural e compreensivo que esse paradigma tenha fortes influências de como eles entendiam uma organização em especial. O resultado da adoção deste paradigma surge linhas teóricas dentro da administração; o taylorismo, fordismo e o fayolismo (LOURENÇO FILHO, 2007).

A administração a partir do exemplar mecanicista vai compreender à organização como uma relação dual, entre os sujeitos e objetos, que os sujeitos sempre tinham a primazia sobre a realidade. A relação entre sujeitos passa a ser objetal. Isso é, a objetivação do outro. Em uma ilustração em que o diretor de uma organização objetiva os trabalhadores, ele os entende como peças de uma grande engrenagem. A ideia de subordinação, submissão é aceita naturalmente em uma organização que segue uma teoria fundada neste paradigma. Essa ideia possibilitou a compreensão que o diretor assumisse o papel de um sujeito que determinava como uma realidade produtiva deveria ser, sem a preocupação de relacionar-se com os objetos, (trabalhadores e ambiente), pois o mesmo é visto como elemento passivo da relação subjetivante do diretor.

A preocupação estava voltada para as tarefas e as estruturas a partir de métodos racionais, burocráticos e mensuráveis para obter resultados econômicos. Esse modelo adotado neste período estava atrelado a uma visão que o 'quebracabeça" já estava montado e mais ainda, que os problemas econômicos, como produzir para atender as nossas necessidades em função de uma lucratividade vinha de encontro as questões cruciais do mercado, na utilização dos recursos naturais que são escassos e às necessidades ilimitadas. O que, e o quanto produzir, como produzir e para quem produzir, esse "quebra-cabeça" estava montado a partir do paradigma mecanicista presente em Taylor, Ford e Fayol.

\section{Desconstituindo a ideia de administração para a ideia de gestão}

A entrada da psicologia e a fisiologia com uma possibilidade de uma nova abordagem sobre o fenômeno econômico passa a ser aceita concorrencialmente com o velho paradigma. Follett (1997) interpreta essa possibilidade nas pesquisas de Holt 
(1914), na sua fórmula circular. A compreensão de Follett (1997) da fórmula de Holt (1914) é que a integração é resultado das relações de duas atividades. Essa compreensão parte do pressuposto que aquela moldura dual entre os sujeitos e os objetos, já não faz mais sentido. Pois, tanto sujeitos e objetos influenciam-se mutuamente. A isso, na compreensão de Follett (1997), ela chama de força integrativa, interativa, são adjetivos possíveis de ser atribuídos por Holt em uma relação processual entre sujeitos, objetos e ambiente.

A interação entre sujeitos, objetos e ambiente, não é mais passiva e sim processual. Aquela compreensão metafisica da linearidade de sujeitos e objetos já não faz mais algum sentido. As pesquisas de Holt (1914) segundo Follett (1997) contribuiu para uma possibilidade de um novo paradigma das atividades entre sujeitos e objetos. Ela deixa de ser compreendida linearmente, dual e passa para a compreensão de sistema integrado que consequentemente, incube uma inauguração moral não dualista.

As experiências resultantes entre sujeitos e objetos são bens sucedida na medida em que a relação seja integrativa. Ora, não é possível a partir desta fórmula a objetivação da realidade. Essa compreensão só é possível com a moldura desenvolvida pela psicologia e a fisiologia.

O paradigma anterior não concebia a montagem do "quebra-cabeça" em simbiose com os elementos externos. É justamente aí, a grande contribuição da psicologia e a fisiologia, quando percebem a influência dos elementos externos no processo comportamental sistêmico (FOLLETT, 1997, p. 39). Essa moldura nos possibilita ter uma perspectiva ampliada das anomalias entre sujeitos e objetos. Saímos daquela compreensão de estágios, ou etapas a serem superadas em erros e acertos do velho paradigma para a compreensão da evolução processual sistêmica. Isso Recai na seguinte intepretação: a evolução não é uma superação ou o abandono de um estágio para alcançar o próximo estágio, mas a ideia que todos os circularmente evoluem.

No campo biológico, a evolução de um organismo vivo acontece circularmente em um sistema integrado. A evolução de uma célula em um determinado tecido contribui para a evolução do organismo como um todo, e a evolução de cada órgão do organismo contribui para a evolução do todo. Observe-se que há uma função na evolução da célula em relação ao organismo como um todo. O que nos leva a 
compreender analogicamente a evolução de uma sociedade, uma empresa e a evolução de um sujeito em seu grupo que contribuem ao mesmo tempo para evolução da sociedade como um todo.

A evolução do sujeito está em função da evolução do grupo -, que está em função da evolução da sociedade. A evolução de uma instituição social contribui para a evolução da sociedade, circulante, todos estão em função da evolução para o todo.

A compreensão de Follett (1997) sobre gestão segue essa linha intuitiva. Esta intuição é perceptível a partir da ideia da fórmula circular de Holt (1914) que demonstra que o comportamento está na relação proporcional ao ambiente, "a realidade está na relação, na atividade mútua. Isto é, não há uma relação fora do sistema. Portanto, em uma situação relacional o sujeito e o objeto são igualmente importantes" (FOLLETT, 1997, p. 38).

Se um dos argumentos fortes de Follett (1997) está ancorado em Holt (1914) é que há uma interação entre sujeitos, objetos e ambiente, isso significa compreender que a realidade só pode ser abarcada a partir desta fórmula relacional, que evolui valorativamente à medida que intensificam os encontros (FOLLETT, 1997, p. 38). Não podemos desprezar aqui que nesta relação também se intensifica os conflitos.

Para Follett (1997), os fisiologistas e os psicólogos ao apontarem a relação entre as contrações musculares e os estímulos, nos assinalam para o reflexo circular. Pois é uma relação funcional entre músculos, estímulos e órgãos de sentidos. O elemento novo apontado por Follett (1997) é que o estímulo não é mais compreendido no velho paradigma, na moldura mecanicista que compreendia o comportamento como uma relação entre sujeitos e objetos, simplesmente, estímulo e resposta. O sujeito precisava ser provocado para reagir ao estímulo por um objeto passivo. A partir do novo paradigma, o sujeito e o objeto são ao mesmo tempo estimulados. Portanto, estímulo e resposta não estão separados, acontecem simultaneamente. Sujeitos e objetos são ao mesmo tempo, estímulo e resposta. O receptor é o emissor, e o emissor é o receptor. Essa é a compreensão de Follett (1997), são duas atividades conjuntas dentro de um sistema sempre aberto.

Desta forma, a compreensão paradigmática da fisiologia e da psicologia é que não é mais possível montar o "quebra cabeça" e nem resolver às anomalias com a velha moldura de agir sobre os sujeitos e agir sobre os objetos (KUHN, 2007). A nova moldura proposta pelos fisiologistas é que entre os sujeitos e os objetos promovem encontros 
interprenetrativos de atividades. Portanto, com esse paradigma fisiológico e psicológico é possível monta o "quebra-cabeça" em uma nova perspectiva que parte da natureza do respeito é a mudança que ela faz na abordagem que causou. Portanto, aquela compreensão mecanicista do entendimento que a relação entre sujeitos e objetos produzia resultados positivos e negativos, agora podemos entender que não constitui mais uma realidade plausível. Com o novo paradigma, não há resultado, e sim momentos de processo que produzem efeitos (FOLLETT, 1997, p. 42).

\section{Gestão como função}

A administração foi fortemente influenciada pela ideia da psicologia comportamentalista que acreditava que para obter resultados nos operários bastava estimulá-los. Percebemos isso presente em Taylor, Ford e Fayol. Essa ideia behaviorista concebia que os músculos residiam o conhecimento e a fonte da força para atingir objetivos e fins.

A percepção de Follett (1997) é que a psicologia sozinha tinha essa compreensão até se aproximar da fisiologia. "Na psicologia e na fisiologia, também encontramos certas conclusões que nos levam a achar que a experiencia em todos os níveis pode ser considerada uma inter-relação na qual a atividade, da relação altera os tornos da própria relação e também a relação em si" (FOLLETT, 1997, p. 54).

Daí um pensamento voltado para quadros, resultados e retroalimentação das informações com constantes estímulos. Se podemos estimular o sujeito para obtermos resultados desejados, então podemos controlá-los e controlar também a fonte de estímulo. Podemos isolar tanto o sujeito e o estímulo e direcioná-lo para fins. Em Follett (1997) essa é a ideia de uma administração diretiva.

A ideia de gestão trás originalmente os reflexos do paradigma da psicologia e a fisiologia em que o comportamento não é mais possível o seu controle a partir de estímulos imediatos (FOLLET, 1997, p. 57) intensificados, ou não, em doses controladas. Não é essa a ideia de gestão em Follett (1997), para ela a gestão é uma função, uma disciplina e não pode ser tratada como uma caixa de ferramenta como um procedimento técnico e métodos e práticas, com algumas empresas tentam enquadrá-la em busca de crescentes resultados econômico-financeiros. Ora, enquanto a administração trabalhava com metas e objetivos para fins, a gestão trabalha com 
propósito, isto é, um telos naquela compreensão aristotélica que toda natureza racionalmente tende a um bem, a uma finalidade, toda natureza vai de encontro a sua realização. O que a define como um bem.

A intervenção no fim da natureza, segundo Aristóteles é uma prática irracional, violenta e injusta. Na sua concepção política, por exemplo, a ideia de corrupção é a perda dos telos da natureza da política. A corrupção é a deterioração do propósito da natureza da política.

Se a gestão é a compreensão que a organização tem um propósito, um telos, então o qual deveria ser a sua realização? Não cabe mais na gestão aquela concepção que uma organização econômica tem seu fim no lucro, ou resultados. Essa visão é tipicamente do velho paradigma que influenciou às organizações econômicas desde os fisiocratas.

Uma organização econômica tem um propósito que vai além dessa visão reducionista econômica. Para Follett (1997, p. 23) uma organização é "uma empresa como uma instituição social, não apenas um veículo financeiro ou de produção, é um prelúdio para uma variedade de questões gerenciais contemporâneas."

$\mathrm{Na}$ administração o diretor da organização estimulava os trabalhadores aspirarem os objetivos da empresa, e ao mesmo tempo, ele estabelecia as metas para alcançar os resultados desejados. Não era uma escolha dos trabalhadores, eles nem se quer participavam da elaboração dos objetivos e metas da empresa. A ideia aqui implícita é de subordinação aos objetivos da empresa e a aceitação de seu fim passivamente. Tal prática na desenvolvia uma consciência política e social, muito menos uma consciência crítica, eram simplesmente operadores, peças endentadas em movimentos sincronizados para resultados.

O propósito se constrói juntos, o propósito de uma sociedade é resultado de uma construção coletiva que se estabelece em uma relação de cidadania. Portanto, sentido de pertença à comunidade. Um líder de uma nação não pode constituir sozinho um propósito de uma nação, e impor aos demais membros da comunidade. 0 propósito é uma construção em consórcio. Desta forma, em uma organização econômica o seu propósito também é uma construção democrática. Os colaboradores devem participar da constituição do propósito da empresa, tal envolvimento pressupõe desde a sua origem uma consciência responsável de desempenho e comprometimento. 
Com essa reviravolta na ideia de administração para a ideia de gestão, conseguimos avançar em alguns pontos importantes; a começar pelos objetivos e metas comuns na prática administrativa que transparecia uma união entre diretor e trabalhadores de forma harmônica (o que de fato era uma ilusão). Eles viviam de aparências e de contradições no sistema administrativo maquiados pelos resultados que ofuscavam à realidade fragmentada e dual.

Na gestão essa realidade foi alterada com a substituição dos objetivos e metas pelo propósito, que em torno dele possibilitava a integração das relações de poderes de interesses conflitantes em uma organização. Pois, o propósito vai além da organização, e transcende os interesses individuais conflitantes. Eis, o novo "quebracabeça", que precisava ser montado a partir do novo paradigma. A constituição do propósito de uma organização econômica, política, social, educacional. Pois envolvem todos no processo em função de resultados compartilhados responsavelmente. Os envolvidos no processo devem saber para o que estão trabalhando, pois, o envolvimento é essencial no processo (FOLLETT, 1997, p. 60).

Se uma organização econômica tem um propósito, também é aceitável que as pessoas tenham o seu propósito, e que também vá além das circunstâncias existenciais e laborais. Essa variável era concebida como anomalias pela administração. O novo paradigma, já não as vê como anomalias, mas possibilidades a serem pensadas e que exige respostas criativas e necessárias.

Ao observar uma escola, percebemos que as práticas educativas ainda permanecem presas ao século $X X$, pois os ambientes de aprendizagem são fechados. Tais práticas correspondem ainda aquela concepção do velho paradigma mecanicista, de controle sobre o aprendente e o seu aprendizado. Onde, o estímulo é liberado paulatinamente à medida que se espera resultados.

Permitir ou promover a excursão dos aprendentes para fora da sala de aula, ou até mesmo da escola em ambientes abertos, passar a ser um estímulo de premiação dos resultados já alcançados, ou seja, são estímulos exagerados para os aprendentes daquilo que já esgotou como possibilidade de aprender em ambientes fechados. As tecnologias têm a função de forçar a queda desse modelo já superado. Com as tecnologias os estímulos não estão mais sobre o controle dos ensinantes e a execução que era uma premiação dos resultados conquistados, perde seu encantamento. 
Portanto, os ambientes virtuais são mais prazerosos do que a prática dos ensinantes, que de longe não concorrem mais com os estímulos midiáticos.

\section{Gestão como processo}

A gestão como compreensão de processo pressupõe que a vontade e a escolha sejam elementos inerentes, e por ser fruto de atos racionais gera uma relação de responsabilidade, todos os envolvidos no processo são corresponsáveis pelos resultados que são compartilhados. Assim, na gestão o propósito não é uma imposição, mas uma escolha consciente e responsável. Na visão de Follett (1997) é natural que a gestão seja democrática e participativa, é da sua natureza. É um comportamento moral que de certa forma, gera obrigações e deveres. "Escolha tem um lugar no processo" (FOLLETT, 1997, p. 62).

A escolha tem aquela ideia kantiana que associa à vontade que nós, naturalmente tendemos a escolher o bem, porque o bem é racional. (Base da compreensão do seu argumento do dever moral). A vontade é fruto no primeiro momento da razão, e no segundo momento resultado do livre-arbítrio. Talvez, aqui possa amenizar o conflito de interesses entre os sujeitos, objetos e o ambiente em que a nossa vontade possa inclinar sempre para a universalidade, recuperando a força da argumentação dos homens de boa vontade. É natural para Kant (1985) que a nossa razão queira resolver os problemas distante das inclinações, das nossas emoções e dos nossos instintos.

Desta forma, podemos pensar que em um processo o ambiente é movediço e que os sujeitos e os objetos sofrem influências e refluências a todo momento. Por isso, que a integração acompanha o mesmo sentido. A ideia de integração em Follett (1997) é muito mais do que acomodação e adaptação ao ambiente em movimento. Sujeitos e objetos e realidade na gestão estão redefinindo a todo momento as suas escolhas, e reavaliando seus propósitos sem cair em uma contradição performativa. Essa é a diferença possível entre os resultados da administração para a gestão. Enquanto a administração leva em consideração à necessidade de adaptação aos objetivos, metas e os fins para conseguir resultados esperados, no entanto, produz uma relação entre sujeitos e a organização econômica compreendida como uma engrenagem. $\mathrm{O}$ mau funcionamento da engrenagem precisa de adaptação e reajustes das peças, daí a sua 
substituição. Eis o modelo mecanicista da administração. Para Follett (1997, p. 64) “não adaptamos nossas atividades aos fins a que se destinam ou aos princípios em que se baseiam." O modelo mecanicista adotado pela administração não leva em consideração esse "quebra-cabeça", sujeitos, objetos e ambiente. Consequentemente, o administrador com o paradigma mecanicista desenvolveu uma consciência possível, produzindo pelos pesquisadores e a comunidades científica da administração que controlar, ordenar levaria a produção bem-sucedida, cria-se ferramentas que auxiliam uma administração das empresas por esses quadros.

Só é possível integrar sujeitos livres a um processo de gestão. Os condicionamentos internos e externos interferem no comportamento dos sujeitos de uma organização. $O$ ato da escolha racional é o que garante o realinhamento do processo ao propósito da organização sem se distanciar das relações laborais em uma organização.

O comportamento moral, tende a ter um alcance maior do que um comportamento ético nas organizações. A ética desde Aristóteles, ainda serve como orientação ou reflexão sobre as nossas ações do que como eu devo fazer para ser feliz. A ética necessita de uma interiorização dos valores, isto é, pressupõe uma crença. Além disso, fica restrita a subjetividade e ao campo privado. E pode facilmente ser manipulada em função de interesses e cair em um relativismo.

Na concepção kantiana, a moral tende a uma objetividade, pois compreende que a moral seria as ações dos sujeitos positivadas em princípios racionais e não subjetivos e valorativos. Enquanto em Aristóteles a preocupação dos sujeitos era o que devo fazer para ser feliz, a moral nos leva à reflexão do que eu posso fazer. O que eu posso fazer, está prescrito em leis que a todos se aplicam no princípio da universalidade e na validade da lei. Desta forma, espera-se que a minha vontade e a minha escolha coincidam com as leis.

Não podemos desassociar uma organização econômica, educacional, política de uma compreensão social. O propósito das organizações e instituições devem convergir para o bem e a moral. À medida que compreendemos uma sociedade moderna com as suas complexidades, a integração dos sujeitos não será só objeto de preocupação da sociologia, mas de todos os seguimentos da sociedade. 


\section{Conclusão}

A concepção do que venha a ser gestão em Follett (1997), inicialmente a compreendemos como um processo em função para. A gestão pode ser delimitada como compreensão de processos, pois implica que a vontade e a escolha dos indivíduos sejam constituintes. Pois, os indivíduos se envolvem no processo, assumem responsabilidades e compartilham resultados. Portanto, entendemos que seria contraditório se Follett (1997) mantivesse tradicionalmente o foco nos elementos isolados (gestores, professores, profissionais da educação e a comunidade), como sustenta Lück (2006). Uma gestão baseada nessa visão revela a fragmentação dual já existente na ideia de administração. Pois a tentativa de Lück (2006) em garantir que a ideia de gestão ancorada no paradigma mecanicista, não permite superar a própria limitação da fragmentação e da descontextualização da realidade educacional. Esse movimento lückiano permanece, ainda preso ao velho paradigma mecanicista quando tentar resolver às fragilidades da administração escolar, quando tenta superar às anomalias do sistema de ensino do século XXI a partir da aglutinação da fragmentação. A Educação não é uma limitação a ser superada com rearranjos modais. Não será uma orientação de sujeitos e objetos em uma organização que propiciará a mudança estrutural. Pois a ideia de orientar à educação a partir da concepção gestacional de Lück (2006), ainda traz em si os elementos da administração no sentido diretivo. Desta forma, permanecer ainda, aqueles elementos mecanicistas; objetivos, metas, controle e resultados. Assim, Lück (2006) ressuscita a ideia de desarmonia das engrenagens que a partir de uma orientação possa resolver o problema de uma organização escolar. Ora, a orientação pressupõe a retomada de um curso que deixamos de seguir e mais ainda, os orientados não têm nenhuma consciência que estão fora do curso, e nem onde se encontra tal curso a seguir. Essa ideia reforça a passividade dos sujeitos presentes na ideia de gestão de Lück (2006).

Lück (2006) ao atribuir à gestão a saga para romper com a ideia de uma realidade educacional fragmentada. Não percebe que a realidade educacional fragmentada não foi produzida pela administração, e sim pelo velho paradigma mecanicista (LOURENÇO FILHO, 2007). Assim, corremos o risco de entrar em uma contradição ao reproduzimos o mito do trabalho de Sísifo. As teorias da administração estão presas ao paradigma mecanicista que tentaram sem sucesso supera à realidade 
educacional fragmentada. Não é da natureza da gestão superar o velho paradigma mecanicista e nem articular à realidade educacional fragmentadas. Portanto, a ideia de uma realidade educacional fragmentada não se sustenta. Bem sabermos que a realidade nunca esteve fragmentada, e que sujeitos e objetos também nunca estiveram em oposição e muito menos, separados epistemologicamente. Portanto, as teorias da administração e da gestão têm um papel mais modesto neste contexto. Não é de ser um paradigma, mas de resolver os problemas oriundos no processo de ensinoaprendizagem. A gestão está muito mais em função de um processo com sujeitos, objetos e ambientes abertos em constante movimentação circulante.

\section{Referências}

BRASIL. Lei no 9.394, de 20 de dezembro de 1996. Estabelece as diretrizes e bases da educação nacional. Brasília, DF: Presidência da República, 1996. Disponível em: http://www.planalto.gov.br/ccivil_03/leis/I9394.htm. Acesso em: 16 mar. 2020.

FOLLETT, Mary Parker. Profeta do gerenciamento. Rio de Janeiro: Qualitymark, 1997. HOLT, Edwin Bissell. The concept of consciousness. Nova York: Macmillan, 1914.

KANT, Immanuel. Resposta à pergunta: que é "esclarecimento"?. In: KANT, Immanuel. Textos seletos. 2. ed. Petrópolis: Vozes, 1985.

KÖCHE, José Carlos. Fundamentos de metodologia científica: teoria da ciência e iniciação à pesquisa. 34. ed. Petrópolis: Vozes, 2015.

KUHN, Thomas S. A estrutura das revoluções científicas. Perspectiva: São Paulo, 2007.

LOURENÇO FILHO, Manoel Bergström. Organização e administração escolar: curso básico. 8. ed. Brasília: Instituto Nacional de Estudos e Pesquisas Educacionais Anísio Teixeira, 2007. 321p. (Coleção Lourenço Filho).

LÜCK, Heloísa. Concepções e processos democráticos de gestão educacional. 9. ed. Petrópolis: Vozes, 2013.

LÜCK, Heloísa. Gestão da cultura e do clima organizacional da escola. 2. ed. Petrópolis: Vozes, 2011.

MARCONI, Marina de Andrade; LAKATOS, Maria Lakatos. Fundamentos de metodologia científica. 6. ed. São Paulo: Atlas, 2009.

Enviado em: 29/03/2019

Aprovado em: 25/06/2020 